\title{
Sintesis Graphene Melalui Iradiasi Microwave Sebagai Sensor Metanol
}

\author{
Endah Fitriani Rahayu ${ }^{* a}$,Alfi Nurul Amalia ${ }^{a}$
}

a Jurusan Kimia Fakultas Matematika dan Ilmu Pengetahuan Alam Universitas Negeri Semarang, Semarang, 50229, Indonesia

INFO ARTIKEL

Diterima 31 Januari 2020

Disetujui 28 April 2020

Key word:
graphene, microwave, sensing
gas, methanol

Kata kunci:

graphene, microwave, sensor

gas, metanol

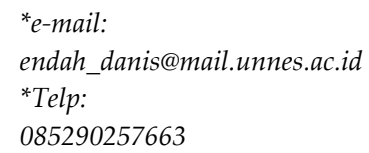

\begin{abstract}
A B STRACT
Graphene is a 2 dimensional material that has unique properties, include has a very high surface area $\left(\sim 2630 \mathrm{~m}^{2} \mathrm{~g}^{-1}\right)$ which can adsorb the target gas. Unlike other gas sensors, graphene sensors can be operated under ambient conditions and at room temperature. The interaction between methanol gas and graphene results is changes in conductivity and resistivity that make graphene a good sensor element. The structure and electronic properties of graphene depend on the synthesis process. Hummers and microwave irradiation methods are chosen because the effective cost production is which producing graphene with high sensitivity to the gas target. Of the three variations of graphene making from Graphene Oxide (GO) via microwave irradiation, 0.1 g-450 Watt, 0.1 g-630 Watt and 0.02 g-450 Watts showed the highest sensitivity in the variation of $0.02 \mathrm{~g}-450 \mathrm{Watts}$ graphene. This indicates that the smaller GO mass and the higher the microwave power form the more optimal graphene properties, especially for gas sensors.
\end{abstract}

\section{A B STRAK}

Graphene merupakan material 2 dimensional yang mempunyai sifat unik salah satunya memiliki luas permukaan sangat tinggi $\left(\sim 2630 \mathrm{~m}^{2} \mathrm{~g}^{-1}\right)$ yang dapat mengadsorbsi gas target. Tidak seperti sensor gas lainnya, sensor graphene dapat dioperasikan di bawah kondisi sekitar dan pada suhu kamar. Interaksi antar gas metanol dengan graphene menghasilkan perubahan pada sifak konduktifitas dan resistensinya yang membuat graphene menjadi elemen sensor yang baik. Struktur dan sifat elektronik graphene tergantung pada proses sintesisnya. Metode Hummers dan microwave irradiation dipilih karena biaya produksi efektif, menghasilkan graphene dengan sensitifitas tinggi terhadap target gas. Dari ketiga variasi pembuatan graphene dari Graphene Oxide (GO) melalui microwave irradiation yaitu 0,1 g-450 Watt, 0,1 g-630 Watt dan 0,02 g-450 Watt menunjukkan sensitifitas paling tinggi pada variasi graphene 0,02 g-450 Watt. Hal ini mengindikasikan semakin kecil massa GO dan semakin tinggi daya microwave membentuk sifat graphene yang lebih optimal terlebih untuk sensor gas.

\section{Pendahuluan}

Minat terhadap graphene telah meningkat secara eksponensial sejak penemuannya karena sifatnya yang luar biasa. Salah satu karakteristik graphene adalah keteraturan dalam susunan atom karbon yang membentuk hampir sempurna. Setiap atom karbon pada lapisan graphene memiliki hibridisasi $\mathrm{sp}^{2}$ yang memiliki orbital $\pi$. Struktur material graphene terdiri dari dua atom tidak ekuivalen yang terhubung dengan jarak antar karbon $1.44 \AA$ [1]. Keteraturan atom graphene yang sangat tinggi dan sangat minim bahkan tanpa cacat timbul sebagai akibat ikatan atom- 
atom karbon yang kuat. Ikatan kimia atomatom karbon pada material graphene merupakan superposisi $2 \mathrm{~s}$, dengan orbital $2 \mathrm{px}$ dan 2py memberikan kesetimbangan energi pada kisi-kisi heksagonal 2D dan ikatan $\sigma$ dengan 3 atom karbon yang berdekatan [2]. Karena mobilitas elektronnya yang tinggi pada suhu kamar, grafit menunjukkan sensitivitas tinggi yang merupakan sifat yang diperlukan dalam aplikasi penginderaan lingkungan dan industri.

Microwave bekerja dengan melewatkan radiasi gelombang mikro pada molekul air, lemak, maupun gula yang sering terdapat pada bahan. Molekul-molekul ini akan menyerap energi elektromagnetik. Di dalam microwave, gelombang mikro yang sudah didistribusikan mampu mengubah arah molekul-molekul dengan kecepatan yaitu sekitar 2450 Megahertz atau 2,45 milyar siklus perdetik. Pergerakan molekul menciptakan panas seiring dengan timbulnya gesekan antara molekul yang satu dengan molekul lainnya. Energi panas yang dihasilkan oleh peristiwa inilah yang berfungsi sebagai agen pemanasan di dalam microwave [3].

Graphene memiliki permukaan spesifik teoretis yang luas $\left(\sim 2630 \mathrm{~m}^{2} \mathrm{~g}^{-1}\right)$. Semua atom dari satu lembar graphene lapisan tunggal dapat dianggap sebagai atom permukaan dan mereka mampu mengadsorpsi molekul gas, sehingga menyediakan area penginderaan besar. Interaksi antara lembaran graphene dan adsorbat dapat bervariasi dari interaksi van der Waals yang lemah untuk ikatan kovalen yang kuat. Semua interaksi ini akan mengganggu sistem elektronik graphene, yang dapat dengan mudah dipantau dengan metode elektronik. Perubahan yang sangat kecil dalam resistensi disebabkan oleh gas pengadsorbsi dapat dideteksi lembaran graphene bahkan hingga tingkat molekul. Dalam artikel ini, kita akan membahas graphene sebagai sensor gas berdasarkan bahan graphene, metode sintesis, aspek, termasuk mekanisme penginderaan, dan perspektif masa depan.

\section{Bahan dan Metode}

Bahan yang digunakan pada penelitian ini, yaitu grafit sintetis, $\mathrm{H}_{2} \mathrm{SO}_{4}$ p.a, serbuk $\mathrm{NaNO}_{3}$, serbuk $\mathrm{KMnO}_{4}, \mathrm{H}_{2} \mathrm{O}_{2}$ p.a, $\mathrm{HCl} 10 \%$, etanol $10 \%$, Ni foam, metanol p.a, aquademin, dan es batu.

\section{Sintesis Graphene Oxide (GO)}

Grafit sintetis ditimbang sebanyak 2 gram, $\mathrm{NaNO}_{3} 1$ gram dan $\mathrm{KMnO}_{4} 6$ gram. Larutan $\mathrm{H}_{2} \mathrm{SO}_{4}$ p.a diukur dengan volume 46 $\mathrm{mL}$ dan $\mathrm{H}_{2} \mathrm{O}_{2}$ p.a dengan volume $6 \mathrm{~mL}$. Selanjutnya seperangkat alat refluks disiapkan di atas magnetic stirrer. Grafit sintetis dan $\mathrm{H}_{2} \mathrm{SO}_{4}$ p.a dicampur dalam seperangkat alat refluks dan diaduk selama 5 menit, kemudian serbuk $\mathrm{NaNO}_{3}$ ditambahkan secara perlahan dan diaduk selama 30 menit pada suhu di bawah $20^{\circ} \mathrm{C}$. Setelah itu serbuk $\mathrm{KMnO}_{4}$ ditambahkan secara perlahan selama 30 menit. Selanjutnya suhu dinaikkan menjadi $40^{\circ} \mathrm{C}$ dan aquades sebanyak $80 \mathrm{~mL}$ dimasukkan, ditunggu selama 30 menit. Kemudian suhu dinaikkan menjadi di atas $75^{\circ} \mathrm{C}$ lalu aquades $200 \mathrm{~mL}$ dan $\mathrm{H}_{2} \mathrm{O}_{2}$ p.a ditambahkan dan diaduk selama 90 menit. Dituggu semalaman hingga terbentuk endapan. Sampel endapan GO yang telah dihasilkan dicuci menggunakan sentrifuga berkali-kali menggunakan etanol $10 \%, \mathrm{HCl} 10 \%$, dan aquademin agar $\mathrm{pH}$ mendekati 7 . Endapan $G O$ dioven pada suhu $80^{\circ} \mathrm{C}$ selama 24 jam untuk menghilangkan kadar airnya.

\section{Sintesis Graphene}

Padatan graphene oxide yang telah kering ditimbang dalam variasi massa yaitu dua kali 0,1 g dan satu kali 0,02 g. Disiapkan juga pelarut air (aquades) masing-masing $200 \mathrm{~mL}$ dan botol sampel untuk tempat sampel. Masing-masing massa padatan graphene oxide dilarutkan dalam $200 \mathrm{~mL}$ aquades dan dilakukan proses ultrasonikasi selama 30 menit. Larutan baku graphene oxide diambil sebanyak $120 \mathrm{~mL}$ diletakkan dalam cawan khusus microwave. Kemudian proses microwave dilakukan dengan variasi daya $50 \%$ (450 watt) dan 70\% (630 Watt) dan $5 \mathrm{~mL}$ larutan pada rentang waktu $1,5,10$, 15, 20 menit.

\section{Preparasi sampel uji resistensi}

Substrat Ni foam diukur dan dipotong berbentuk lingkaran dengan diameter $3 \mathrm{~cm}$ sebanyak tiga buah. Larutan graphene yang digunakan untuk membuat sampel uji resistensi adalah 0,015 g dalam $15 \mathrm{~mL}$ (1 ppm). 
Substrat yang sudah dipotong kemudian direndam pada masing-masing larutan graphene dan dimasukkan ke dalam alat ultrasonikator. Proses ini dilakukan 30 menit agar graphene dapat tersebar merata pada substrat Ni foam. Kemudian sampel dikeringkan dalam oven pada suhu $80^{\circ} \mathrm{C}$ selama 2 jam.

\section{Hasil dan Pembahasan}

Seiring dengan pemanasan $G O$ tejadi pula pemutusan ikatan antara karbon dengan gugus gugus yang menempel padanya. Graphene oxide mempunyai sifat hidrofilik yaitu menyukai air sehingga mudah larut dalam air menghasilkan larutan berwarna coklat, sedangkan graphene sendiri mempunyai sifat hidrofobik yang sukar larut dalam air. Semakin lama proses microwave semakin keruh dan tidak larut pula larutan $G O$ yang mengindikasikan bahwa graphene semakin banyak terbentuk.

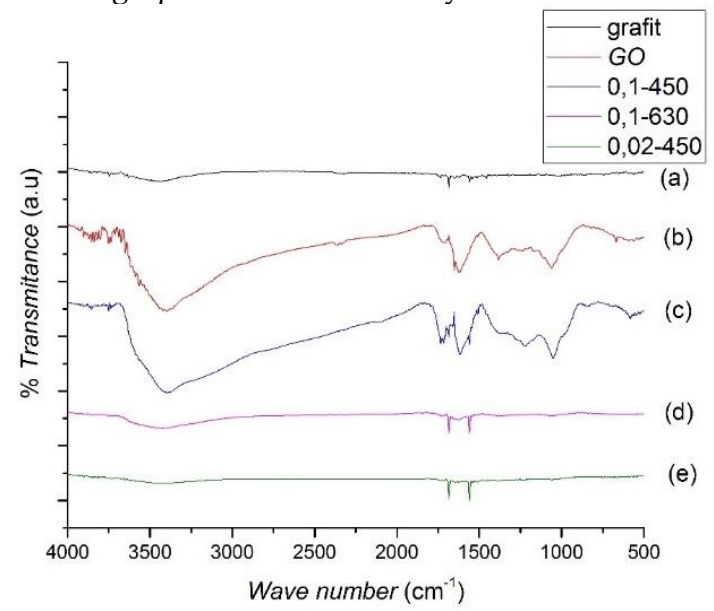

Gambar 1. Grafik hasil uji spektra FTIR (a) grafit, (b) GO, (c) graphene dengan variasi $0,1 \mathrm{~g}$ dalam 450 Watt, (d) graphene dengan variasi 0,1 $\mathrm{g}$ dalam 630 Watt dan (e) 0,02 g dalam 450 Watt.

Beberapa gugus fungsi dari $\mathrm{GO}$ dapat diketahui seperti $\mathrm{O}-\mathrm{H}, \mathrm{C}=\mathrm{O}, \mathrm{C}-\mathrm{OH}$, and $\mathrm{C}-\mathrm{O}$ [4]. Karakteristik pada puncak panjang gelombang $\sim 3464 \mathrm{~cm}^{-1}$ diyakini sebagai $\mathrm{O}-\mathrm{H}$ stretching dari golongan hidroksil dan karbonil, karakteristik lainnya terdapat pada puncak panjang gelombang $\sim 1639 \mathrm{~cm}^{-1}$ yang merupakan $\mathrm{C}=\mathrm{O}, \sim 1288 \mathrm{~cm}^{-1}$ merupakan $\mathrm{C}-\mathrm{OH}$, $\sim 1493 \mathrm{~cm}^{-1}$ menandakan keberadaan $\mathrm{C}=\mathrm{C}$ dari domain grafit yang belum teroksidasi, dan $\sim 1003 \mathrm{~cm}^{-1}$ merupakan C-O yang juga diyakini sebagai golongan asam karboksilat dan karbonil [5]. Berikut merupakan grafik hasil spektra FTIR pada gambar 1.

Variasi ketiga pembuatan graphene yang kedua yaitu menggunakan massa 0,02 g dan daya microwave 450 Watt diperoleh ikatan $\mathrm{O}-\mathrm{H}$ asam karboksilat dengan cekungan kecil pada panjang gelombang $3420,3 \mathrm{~cm}^{-1}$ yang mempunyai transmitansi sebesar $96,42 \%$ (absorbansi $=0,0158$ ), ikatan $\mathrm{C}=\mathrm{O}$ pada panjang gelombang $1685,7 \quad \mathrm{~cm}^{-1} \quad$ mempunyai transmitansi sebesar $\quad 96,58 \%$ (absorbansi $=0,0151$ ), dan ikatan $\mathrm{C}=\mathrm{C}$ alkena pada panjang gelombang $1559,99 \mathrm{~cm}^{-1}$ mempunyai transmitansi $96,42 \%$ (absorbansi=0,01583). Hal ini menandakan variasi ketiga lebih banyak tereduksi dibandingkan dengan variasi pertama dan kedua, dibuktikan dengan ikatan $\mathrm{O}-\mathrm{H}$ asam karboksilat yang mempunyai absorbansi paling rendah. Variasi ketiga dengan variasi pertama sama sama menggunakan daya microwave 450 Watt yang membedakan adalah massa $G O$ yang direduksi. Keduanya memberikan hasil yang berbeda secara signifikan, sehingga dapat disimpulkan bahwa massa GO dapat ๓nempengaruhi proses reduksi oleh gelombang microwave yaitu semakin kecil massa GO maka semakin besar kemungkinan tereduksi dalam daya yang sama.

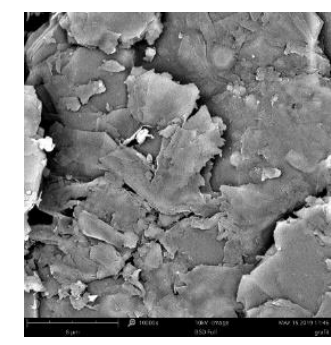

(a)

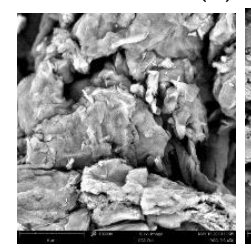

(c.)

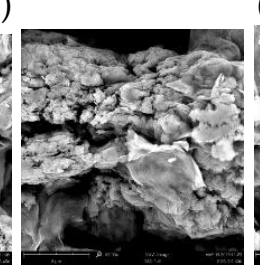

(d)

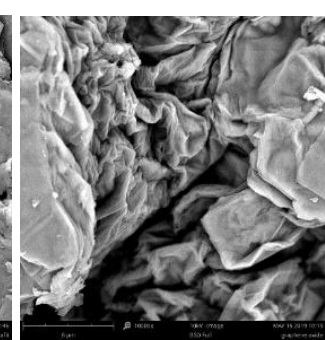

(b)
Gambar 2. Hasil karakterisasi SEM (a) Grafit perbesaran 10000x, (b) GO perbesaran 10000x, (c) graphene variasi 0,1 g-450 Watt perbesaran 10000x, (d) graphene variasi 0,1 g-630 Watt perbesaran 10000x dan (e) graphene variasi 0,02 g-450 Watt perbesaran 10000x. 
Analisis menggunakan SEM (Scanning Electron Microscopy) bertujuan untuk mengetahui morfologi permukaan dan ukuran butiran suatu sampel. Berdasarkan analisis menggunakan SEM, diperoleh morfologi ruang pada sampel grafit, $G O$ dan graphene dengan variasi $0,1 \mathrm{~g}$ - $450 \mathrm{Watt}, 0,1 \mathrm{~g}$ - 630 Watt dan 0,02 $\mathrm{g}$ - 450 Watt dengan perbesaran masing masing adalah 10000x.

Dari gambar SEM, jelas bahwa grafit mempunyai lembaran-lembaran dan gambar SEM dari GO yang terkelupas. Ini jelas menunjukkan bahwa bagaimana lembaran graphene dikelupas [6]. Graphene oxide dan graphene keduanya efisien dikelupas untuk membentuk lembaran tipis yang terpisah dan berkerut untuk membentuk struktur berpori. Sebagai perbandingan, graphene terdiri dari lembaran yang lebih tipis dan pori-pori lebih kecil dari graphene oxide [7]. Menurut [4], dengan adanya hasil SEM dimensi dapat diamati. Struktur lipatan dapat ditemukan pada permukaan dan tepi dari bubuk $r G O$ (graphene). Lipatan tersebut adalah morfologi khas dari graphene. Alasan yang mungkin merupakan perlakuan pada suhu tinggi dan waktu lama.

Mekanisme penginderaan gas dari graphene umumnya berasal dari adsorpsi / desorpsi molekul gas (yang bertindak sebagai donor atau akseptor elektron) pada permukaan graphene, yang mengarah pada perubahan konduktansi graphene [8].

Dalam penelitian ini digunakan uap metanol sebagai zat yang dideteksi. Uap metanol tidak masuk ke dalam graphene melainkan hanya di permukaan sehingga uap metanol tersebut mudah untuk dilepaskan kembali. Uap metanol bertindak sebagai dopan sementara ke lapisan graphene dan mengubah konsentrasi elektronik lokalnya, perubahan resistensi yang diamati mengindikasikan bahwa molekul uap terikat dekat sampel, dengan demikian mengubah lingkungan elektrostatik pembawa muatan. Gugus $-\mathrm{CH}_{3}$ terikat dengan lemah dengan graphene [9]. Untuk reaksi pada permukaan $\mathrm{sp}^{2}$ gugus alkil dan alkil halida memungkinkan diidentifikasikan dalam ikatan kovalen C-C [10]. Ikatan antarmolekul kovalen bersifat lemah sehingga untuk memutuskannya hanya diperlukan energi yang kecil. Di sisi lain, jika senyawa terlalu kecil atau memiliki interaksi terlalu lemah permukaan senyawa akan terdesorbsi dari permukaan sebelum reaksi apapun dapat terjadi [10].

Hasil karakterisasi nilai resistensi pada tiga variasi graphene dan tiga variasi laju alir uap metanol menggunakan alat LCR-Meter 9183 diketahui pada grafik berikut ini.

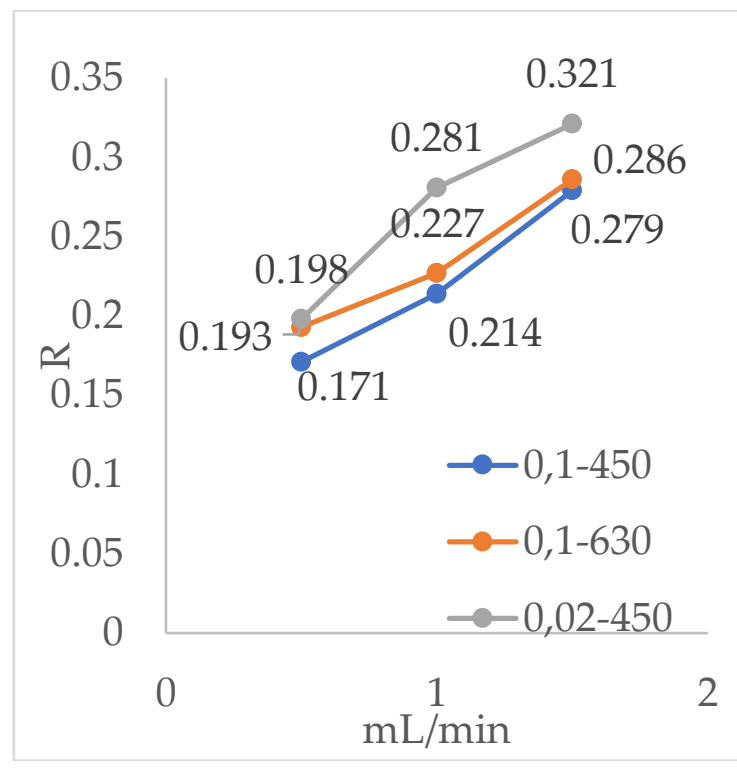

Gambar 3. Grafik hasil uji resistensi uap metanol pada graphene.

Gambar 3 menunjukkan hasil resitensi terhadap laju alir uap metanol. Pada variasi pertama yaitu graphene yang telah disintesis dengan variasi $0,1 \mathrm{~g}$ menggunakan daya 450 Watt dihasilkan resistensi pada laju alir uap metanol $0,5 \mathrm{~mL} / \mathrm{min}$ sebesar $0.171 \Omega$ pada laju alir $1 \mathrm{~mL} / \mathrm{min} 0.214 \Omega$ dan laju alir $1,5 \mathrm{~mL} / \mathrm{min}$ $0,279 \Omega$. Hal ini sesuai teori yaitu apabila semakin banyak uap molekul menyentuh sensor maka resitensi semakin naik.

Variasi kedua yaitu graphene yang disintesis pada variasi 0,1 $\mathrm{g}$ menggunakan daya 630 Watt dihasilkan resistensi yang lebih tinggi dari variasi pertama yaitu pada laju alir 0,5 $\mathrm{mL} /$ min resistensi sebesar $0,193 \Omega$ kemudian pada laju alir $1 \mathrm{~mL} / \mathrm{min}$ resistensi sebesar 0,227 $\Omega$ dan pada laju alir $1,5 \mathrm{~mL} / \mathrm{min}$ resistensi sebesar 0,286 $\Omega$. Variasi kedua lebih tinggi resistensinya daripada variasi pertama, hal ini dikarenakan varasi kedua menggunakan daya microwave yang lebih besar, kemungkinan terbentuk graphene semakin banyak, sehingga kemampuan mendeteksi molekul uap metanol menjadi semakin besar. Variasi ketiga 
menggunakan variasi sintesis graphene 0,02 g dengan daya 450 Watt menghasilkan resistensi yang paling tinggi yaitu pada laju alir 0,5 $\mathrm{mL} / \mathrm{min}$ resistensi sebesar 0,198 $\Omega$, kemudian pada laju alir $1 \mathrm{~mL} / \mathrm{min}$ sebesar $0,281 \Omega$ dan laju alir $1,5 \mathrm{~mL} / \mathrm{min}$ sebesar $0,321 \Omega$. Hal ini membuktikan bahwa variasi ketiga memiliki kemampuan mendeteksi yang paling bagus di antara dua variasi lainnya.

\section{Kesimpulan}

Variasi massa GO dan daya microwave mempengaruhi nilai absorbansi pada panjang gelombang yang sama. Semakin sedikit massa dan semakin tinggi daya maka GO semakin tereduksi. Berdasarkan hasil uji spektra FTIR menunjukkan terdapat perubahan struktur. Semakin sedikit massa dan semakin tinggi daya maka gugus fungsi semakin berkurang. Gugus fungsional pada GO dan graphene yang dapat diidentifikasi adalah ikatan $\mathrm{O}-\mathrm{H}$ asam karboksilat, ikatan rangkap $\mathrm{C}=\mathrm{C}$ alkena dan ikatan C-O. Pengaruh massa GO dan daya microwave mempengaruhi kepekaan sensor. Massa paling sedikit (0,02 g) dengan daya microwave paling tinggi (630 Watt) menghasilkan sensor dengan kepekaan paling baik. Resistensi dapat berubah seiring dengan perubahan lingkungan di sekitarnya. Semakin tinggi stimulus uap metanol yang diberikan maka resistensi yang dihasilkan akan semakin tinggi.

\section{Daftar Pustaka}

1. Terrones, M.; Botello-Méndez, A.R.; Campos-Delgado, J.; López-Urías, F.; Vega-Cantú, Y.I.; Rodríguez-Macías, F.J.; Elías, A.L.; Muñoz-Sandoval, E.; CanoMárquez, A.G.; Charlier, J.-C. Graphene and graphite nanoribbons: Morphology, properties, synthesis, defects and applications. Nano Today 2010, 5, 351-372, doi:10.1016/j.nantod.2010.06.010.

2. Choi, W.M.; Shin, K.S.; Lee, H.S.; Choi, D.; Kim, K.; Shin, H.J.; Yoon, S.M.; Choi, J.Y.; Kim, S.W. Selective growth of $\mathrm{ZnO}$ nanorods on $\mathrm{SiO} 2 / \mathrm{Si}$ substrates using a graphene buffer layer. Nano Research 2011, 4, 440-447, doi:10.1007/s12274-0110100-6.

3. Ningrum, A.S. dan D.K. Pengeringan
Kunyit Menggunakan Microwave dan Oven. Universitas Diponegoro 2008.

4. Cao, N.; Zhang, Y. Study of Reduced Graphene Oxide Preparation by Hummers' Method and Related Characterization. Journal of Nanomaterials 2015, 2015, doi:10.1155/2015/168125.

5. Chen, W.; Yan, L.; Bangal, P.R. Preparation of graphene by the rapid and mild thermal reduction of graphene oxide induced by microwaves. Carbon 2009, 48, 1146-1152, doi:10.1016/j.carbon.2009.11.037.

6. Arthi G, P.B.; BD, L. A Simple Approach to Stepwise Synthesis of Graphene Oxide Nanomaterial. Journal of Nanomedicine $\mathcal{E}$ Nanotechnology 2015, 06, 1-4, doi:10.4172/2157-7439.1000253.

7. Xu, B.; Yue, S.; Sui, Z.; Zhang, X.; Hou, S.; Cao, G.; Yang, Y. What is the choice for supercapacitors: Graphene or graphene oxide? Energy and Environmental Science 2011, 4, 2826-2830, doi:10.1039/c1ee01198g.

8. Lu, G.; Ocola, L.E.; Chen, J. Reduced graphene oxide for room-temperature gas sensors. Nanotechnology 2009, 20, 445502, doi:10.1088/09574484/20/44/445502.

9. Liu, X.Y.; Zhang, J.M.; Xu, K.W.; Ji, V. Improving SO 2 gas sensing properties of graphene by introducing dopant and defect: A first-principles study. Applied Surface Science 2014, 313, 405-410, doi:10.1016/j.apsusc.2014.05.223.

10. Held, P.A.; Fuchs, H.; Studer, A. Covalent-Bond Formation via OnSurface Chemistry. Chemistry - A European Journal 2017, 23, 5874-5892, doi:10.1002/chem.201604047. 